\title{
PRODUTOS ORGÂNICOS: AS FERRAMENTAS DE MARKETING PARA SUA SUSTENTABILIDADE ECONÔMICA
}

\author{
Graziela Oste Graziano \\ Doutora em Administração Universidade Nove de Julho - UNINOVE \\ Professora da Universidade Metodista de Piracicaba - UNIMEP \\ graziela_oste@terra.com.br
}

Milton de Abreu Campanario

PhD - UNINOVE e FEA-USP

campanario@uninove.br

Milton de Freitas Chagas Filho

Doutor em Engenharia Aeronáutica e Mecânica Instituto Tecnológico de Aeronáutica - ITA miltonfc@uninove.br

\section{RESUMO}

Partindo de uma atividade que respeita as limitações ambientais - a produção de orgânicos - examinada neste artigo, trata dos programas mercadológicos implementados pelos produtores de orgânicos que possam contribuir para se alcançar a sustentabilidade econômica do setor. Os produtos orgânicos, devido às dificuldades do consumidor em avaliar os seus atributos, são classificados como "bens de crença". Este tipo de bens demanda ações mercadológicas com capacidade de assegurar reputação para a marca das empresas e relações de confiança entre os produtores e consumidores. A confiabilidade no longo prazo só pode ser alcançada com introdução dos programas de Marketing de Relacionamento. O objetivo principal deste artigo foi analisar quantitativa e qualitativamente a introdução de programas de Marketing de Relacionamento em suas vertentes: Programas de Fidelização e Programas de Endomarketing. A amostra por conveniência envolveu vinte quatro empresas produtoras de orgânicos. Como resultado, verificou-se o uso do Programa de Fidelização em todas as empresas da amostra. Contrariando a recomendação teórica, seu uso precedeu a introdução do Programa de Endomarketing utilizado em dez das empresas pesquisadas.

Palavras-Chave: Desenvolvimento sustentável; Produtos orgânicos; Marketing de Relacionamento.

\section{ORGANIC PRODUCTS: THE MARKETING TOOLS FOR YOUR ECONOMIC SUSTAINABILITY}

\section{ABSTRACT}

Sustainable development is based essentially on the balance between different needs related to limited environmental, economic and social resources. From an eco-friendly activity that respects environmental limits - the production of organic products - it is examined marketing programs implemented by organic producers that can contribute to achieving economic sustainability of the sector. Due to difficulties in evaluating the consumer attributes, organic products are classified as "belief commodity". This type of goods demands market actions to ensure capacity for the brand reputation of companies and trust between producers and consumers. The proposition of the research is that the long-term reliability can only be achieved with the introduction of marketing relationship programs. The main objective of this study was to analyze quantitatively and qualitatively the introduction of Relationship Marketing Programs, including its two versions: loyalty programs and endomarketing. The convenience sample involves twenty four companies producing organic goods. As a result, there was the use of loyalty program in all the firms investigated. Contrary to the theoretical recommendation, its use preceded the introduction of the program endomarketing - used in ten of the companies surveyed.

Key Words: Sustainable development; Organic products; Relationship Marketing.

\section{* Apoio recebido do Fundo de Apoio a Pesquisa - FAP/UNINOVE}




\section{INTRODUÇÃO}

Pouco tempo após a Segunda Guerra mundial em 1949, a ONU patrocinou uma conferência sobre a Conservação e Utilização de Recursos (UNSCCUR), realizada em Lake Sucess, nos EUA. A preocupação com a utilização dos recursos naturais foi suplantada pelo encanto como a 'revolução verde' que, mesmo aceitando a monocultura dependente de agrotóxicos e de adubos inorgânicos, prometia terminar rapidamente com a insuficiência de alimentos para uma população global em franco crescimento. Nos anos 1960, a bióloga marinha Rachel Carson lança o livro "Silent Spring" (Primavera Silenciosa) no qual analisa o impacto de alguns pesticidas sintéticos de hidrocarbonetos clorados, sobre a fauna e a sua possibilidade de invadir a cadeia alimentar humana e alerta a respeito das consequências danosas para o meio ambiente e para a humanidade, devidas ao uso de agrotóxicos. A questão ambiental, que se pauta inicialmente por princípios marcadamente preservacionistas, envolve, com o tempo, novas reivindicações fundamentadas em valores centrados na natureza (ecocêntricos), substituindo os valores antropocêntricos que reinavam desde a época renascentista.

Em 1987, a Comissão Mundial sobre Meio Ambiente e Desenvolvimento das Nações Unidas, ao lançar o relatório conhecido como o relatório Bruntland WCED (1987), incorpora uma nova estratégia de desenvolvimento um modelo econômico de crescimento, capaz de suprir as necessidades da população atual, promovendo o seu bem-estar, sem comprometer as condições de desenvolvimento das gerações futuras.

A história da sustentabilidade, iniciada com a preservação do meio ambiente e da biodiversidade, continua com a discussão sobre as necessidades do crescimento produtivo levando em consideração os limites ambientais e a finitude dos recursos (GOODLAND et al., 1997). Em seu sentido mais amplo, a estratégia de desenvolvimento sustentável visa à promoção da harmonia entre os seres humanos e a natureza, incluindo as dimensões econômica, ambiental e social.

A capacidade de geração de serviços dos ecossistemas depende da manutenção de certos componentes ecossistêmicos, tais como, população e cadeia alimentar, dentro de limites específicos. Uma vez vencidos estes limites o sistema poderá entrar em colapso e sua produtividade torna-se nula", conclui Seroa da Motta, em (1997).

Iniciando pelos produtos da agricultura orgânica, considerada por definição uma atividade sustentável, o objetivo nesse artigo é investigar as práticas mercadológicas que possam contribuir para se alcançar a sustentabilidade econômica deste setor. O conceito de agricultura orgânica adotado neste artigo é apresentado no texto abaixo:

Agricultura orgânica é o sistema de manejo sustentável da unidade de produção com enfoque sistêmico que privilegia a preservação ambiental, a agrobiodiversidade, os ciclos biogeoquímicos e a qualidade de vida humana. A agricultura orgânica aplica os conhecimentos da ecologia no manejo da unidade de produção, baseada numa visão holística da unidade de produção. Isto significa que o todo é mais do que os diferentes elementos que o compõem. Na agricultura orgânica, a unidade de produção é tratada como um organismo integrado com a flora e a fauna.

Portanto, é muito mais do que uma troca de insumos químicos por insumos orgânicos/biológicos/ecológicos. Assim, o manejo orgânico privilegia o uso eficiente dos recursos naturais não renováveis, aliado ao melhor aproveitamento dos recursos naturais renováveis e dos processos biológicos, à manutenção da biodiversidade à preservação ambiental, ao desenvolvimento econômico, bem como à qualidade de vida humana. (EMBRAPA, 2011).

Revista de Gestão Social e Ambiental - RGSA, São Paulo, v. 5, n. 3, p. X-XX, set./dez. 2011. 
Metodologicamente trata-se de um estudo exploratório e descritivo, que conta com levantamento de dados a respeito das ações mercadológicas - consideradas essenciais para se conseguir a sustentabilidade econômica - de 24 indústrias produtoras de orgânicos.

A justificativa para o artigo deve-se à falta deste tipo de estudo que reúne uma área com pesquisas que possam contribuir para a sua sustentabilidade econômica. Uma frase de incentivo para esta pesquisa vem de Darolt (2001): "Apesar de existir uma demanda crescente por alimentos orgânicos, a pesquisa mostrou que o processo de comercialização ainda é bastante complexo, sendo considerado como um dos principais entraves junto com a falta de recursos dos produtores" (DAROLT, 2001).

\section{OS PRODUTOS ORGÂNICOS}

Por abranger um sistema de produção capaz de manter a conservação dos solos, a biodiversidade e a integridade dos ecossistemas, contribuindo para a melhora da qualidade de vida das pessoas, a agricultura orgânica está ganhando espaço. O setor de orgânicos no mundo e no Brasil vem crescendo nos últimos anos. Entre 2001 e 2007, o mercado mundial passou de um total de 21 bilhões de dólares para 46 bilhões (BID/FUMIN, 2011). No Brasil, de acordo com o BID/FUMIN (2011), no início da década de 1990 o mercado de orgânicos, que crescia 10\% a.a., chegou a $50 \%$ a.a de 2006-2009.

Este crescimento da quantidade produzida e vendida se acompanhada por um acréscimo proporcional ao número de produtores de produtos orgânicos, chama a atenção dos pesquisadores para os estudos sobre as ações e os instrumentos para alcançar a sustentabilidade econômica desses produtos.

De acordo com a Instrução Normativa 007/99, do Ministério da Agricultura Pecuária e Abastecimento, os produtos orgânicos são classificados da seguinte forma:

\footnotetext{
Sistema orgânico de produção agropecuária e industrial é todo aquele em que se adotam tecnologias que otimizem o uso dos recursos naturais e socioeconômicos, respeitando a integridade cultural e tendo por objetivo a autossustentação no tempo e no espaço, a maximização dos benefícios sociais, a minimização da dependência de energias não renováveis e a eliminação do emprego de agrotóxicos e outros insumos artificiais tóxicos, organismos geneticamente modificados (OGM) ou radiações ionizantes em qualquer fase do processo de produção, armazenamento e de consumo, e entre os mesmos privilegiando a preservação da saúde ambiental e humana, assegurando a transparência em todos os estágios da produção e da transformação (BRASIL, 1999, p. 1).
}

A agricultura orgânica tem por princípio estabelecer sistemas de produção fundamentados num conjunto de procedimentos que envolvam a planta, o solo e as condições climáticas, produzindo um alimento sadio e com suas características e sabor originais, que atenda às expectativas dos seus consumidores. Além de apresentar sustentabilidade ambiental, a agricultura orgânica melhora a qualidade de vida da população rural satisfazendo suas necessidades socioeconômicas e fortalecendo suas organizações sociais e culturais.

Todo produto obtido em sistema orgânico de produção agropecuária ou industrial, seja in natura ou processado, é considerado orgânico. O conceito abrange os processos atualmente conhecidos como "ecológico, biodinâmico, natural, sustentável, regenerativo, biológico, agroecológico e permacultura".

Revista de Gestão Social e Ambiental - RGSA, São Paulo, v. 5, n. 3, p. X-XX, set./dez. 2011. 
Produtor orgânico, segundo a Instrução, pode ser tanto o produtor de matérias-primas como seus processadores (ORMOND, et al, 2002, p.5).

$\mathrm{Na}$ indústria de alimentos, a procura por qualidade está crescendo num ritmo paralelo ao crescimento dos produtos orgânicos. Os consumidores estão dispostos a pagar mais por produtos que consideram de qualidade. Entretanto, os atributos desejáveis dos alimentos possuem características tangíveis e intangíveis. Os tangíveis são determinados pelo sabor e pela apresentação - variedades, cor e tamanho. As qualidades dos produtos orgânicos, em geral, não são tangíveis e a possibilidades de sua segmentação e diferenciação demandam certificação e, em vários casos, os consumidores demandam a rastreabilidade do processo produtivo.

Segundo Douglas (1992), os bens e serviços podem ser classificados em bens de pesquisa, de experiência e de crença, com base na dificuldade e no custo do consumidor para avaliar a sua qualidade na hora da compra. O consumidor não consegue distinguir se o produto possui os atributos por ele desejados. São os chamados bens de crença. Os bens de crença, devido à dificuldade de avaliação dos atributos, apresentam mais altos custos de informação.

De acordo com Souza (2000), os produtos orgânicos classificam-se como bens de crença, pois apresentam atributos de qualidade específicos, não identificáveis mediante simples observação. Para o autor, qualidade relaciona-se não apenas com aspectos visuais, tais como aparência ou sanidade, mas também, com a isenção de produtos químicos. A qualidade diz respeito também à confiabilidade na presença de propriedades específicas nos produtos, ou seja, refere-se à confiança com que os consumidores podem comprar determinados produtos, se estiverem buscando características específicas. A certificação e a rastreabilidade são instrumentos de redução da assimetria de informações entre os agentes, melhorando a capacidade dos consumidores para identificar atributos de difícil observação.

Entretanto, os acréscimos nos preços destes produtos incentivam comportamentos oportunistas por parte de empresas e/ou produtores. Esse fato chama a atenção de que é preciso criar reputação para o marca da empresa e relações de confiança entre os produtores e consumidores. Este tipo de confiança só pode ser estabelecido no longo prazo. Os melhores instrumentos para alcançar este objetivo e com ele a sustentabilidade econômica dos produtores de orgânicos recaem sobre o uso dos Programas de Marketing de Relacionamento.

\section{DO MARKETING TRANSACIONAL (MT) AO MARKETING DE RELACIONAMENTO (MR)}

A Industrialização, acompanhada pela produção em massa, ao reduzir os custos dos produtos, aumentando ininterruptamente o mercado e os pontos de venda, afastou o produtor do consumidor. Este espaço foi ocupado pelo Marketing Transacional (MT).

No final de século XX, o desenvolvimento da tecnologia de informação havia propiciado condições para o aumento da variedade dos produtos com menores despesas de produção. No cumprimento de seu objetivo maior de obter lucros, as empresas iniciaram a produção destinada a certos tipos de cliente - ou segmentaram o mercado. A tecnologia de informação podia ajudar as empresas, tendo na produção específica, quanto na determinação dos desejos específicos dos segmentos de clientes atendidos. Notava-se uma demanda crescente por variedade maior de produtos e a consequente redução do ciclo de vida dos produtos.

A competição entre as empresas passava mais e mais para atendimento de nichos específicos e muitas empresas de fabricação em massa faliram. O ápice deste processo ocorreu com a junção do processo de produção em massa com o princípio da individualização, denominada de mass customization por Davis (1990), no seu livro "Futuro perfeito", publicado pela primeira vez em 1987. O autor apontava para uma tendência que iria substituir a fabricação e a distribuição em ampla escala de produtos padronizados, pelo princípio da individualização dos produtos, já realidade em alguns ramos produtivos. 
Estas mudanças foram seguidas por estratégias mercadológicas focadas no anseio de atender as aspirações dos consumidores dos segmentos alvos definidos pelas empresas e, na sequência, ao atendimento do consumidor individual. $\mathrm{O}$ crescimento ininterrupto do setor de serviços e a redução comparativa do setor industrial levaram naturalmente o estudo das ações mercadológicas para o mercado de serviços, no qual o atendimento individualizado é padrão.

Nascia o Marketing de Relacionamento - orientado para o longo prazo - e tomava o seu lugar ao lado do Marketing Transacional (MT) - focado nas transações comerciais a curto prazo que, de acordo com Grönroos (1994), beneficia mais empresas com estratégias transacionais focadas no mercado de massa. Berry (1983) definiu Marketing de Relacionamento como a atração, a manutenção e aumento de relação com os entes. Para ele, a conquista de novos clientes deveria ser vista apenas como um passo intermediário no processo de marketing.

Sheth e Parvatiyar (1995) identificaram cinco forcas macroambientais responsáveis pelo crescimento da orientação do Marketing de Relacionamento na era pós-industrial. São elas: (1) o rápido avanço tecnológico, principalmente da tecnologia da informação; (2) a adoção de programas de qualidade total nas empresas; (3) crescimento do setor de serviços nas economias; (4) os processos de desenvolvimento organizacional com o empoderamento de indivíduos e equipes; e (5) aumento da intensidade da competição levando a preocupação com retenção dos clientes. Essas forças, de acordo com os autores, ao promoverem interação mais direta entre os produtores e consumidores de bens e serviços, incentivam a adoção do Marketing de Relacionamento. Quanto à retenção do consumidor, na época de 1980 havia estudos, como os de Rosenberg; Czepiel (1984), demonstrando que a retenção de consumidores é mais barata e mais sustentável em relação à conquista de novos consumidores.

O marketing de relacionamento conforme, alertam Olbrzymek et al. (2005), consiste em estudo dos clientes atuais, em primeiro lugar para poder distinguir os clientes mais relevantes para os propósitos da empresa, para que em segundo lugar se possa trabalhar no sentido de fidelizar esse cliente. $\mathrm{O}$ conhecimento sobre os hábitos e os desejos do cliente permitirá a antecipação de suas necessidades, de forma que não queira transacionar com outra organização.

As estratégias mercadológicas se voltaram para o Marketing de Relacionamento que destaca o imperativo de manter o relacionamento com os clientes no longo prazo, buscando sempre a sua fidelização, como forma da organização alcançar maior satisfação dos clientes e competitividade sustentável para a empresa.

Os benefícios para o cliente consistem em: (1) obtenção contínua ou periódica de serviços que são pessoalmente importantes e customizados às suas necessidades; (2) redução do risco da compra, por já conhecerem o fornecedor; (3) oferta benefício social (status) por estarem recebendo um serviço personalizado; (4) maior bem-estar e qualidade de vida (BRETZKE; RIBEIRO; DOURADO, 1998).

\subsection{Endomarketing: a qualidade do serviço prestado}

De acordo com Kotler e Armstrong (2000), marketing externo seria o processo de preparação, determinação do preço, distribuição e promoção, enquanto o marketing interno ou endomarketing "pode ser entendido como o processo de treinamento e motivação feito com os funcionários para que atendam bem os clientes" (KOTLER, 2000, p. 456). Para o autor, marketing interno deve preceder o marketing externo, pois um serviço não pode ser proporcionado antes da preparação dos funcionários sobre a importância da qualidade do serviço prestado para o cumprimento dos objetivos da empresa.

Antes de tudo, as empresas precisam conscientizar os seus funcionários sobre a importância de propiciar aos clientes um valor superior às suas expectativas. Para isso os funcionários são vistos como clientes e a empresa terá que trabalhar no sentido de proporcionar um ambiente favorável.

Revista de Gestão Social e Ambiental - RGSA, São Paulo, v. 5, n. 3, p. X-XX, set./dez. 2011. 

afirma:

Bekin (1995), que de acordo com Brum (2010) introduziu o endomarketing no Brasil,

[...] é fundamental renovar a própria concepção de marketing, que não pode ser visto mais como uma atividade isolada. É preciso que a realidade do marketing esteja presente na empresa de ponta a ponta do departamento de finanças às vendas, do desenvolvimento do produto aos recursos humanos. Só assim todos poderão compreender a necessidade de que suas ações estejam orientadas para o cliente como parte da estratégia final da empresa (Bekin, 1995, p. 7).

De acordo com Inkotte (2000), “o Endomarketing é um ensaio para fazer crescer o funcionário como indivíduo e a empresa como organização" (INKOTTE, 2000, p. 122). Os colaboradores da empresa são considerados como seus primeiros clientes e os esforços das empresas seriam direcionados, em primeiro plano, para eles.

As atividades de endomarketing, para Camelo e Vidal (2006), não devem estar focadas somente na melhoria incremental, por meio de ações pontuais e esporádicas, mas sim, na criação de um ambiente de crescimento individual, que favoreça o desempenho coletivo na busca do aprendizado organizacional contínuo. Os principais objetivos do endomarketing, para Kotler (1993) são:

1 - Criação de canais de comunicação entre todos os colaboradores para a eliminação de conflitos interpessoais e incentivo às trocas de experiências, gerando assim uma melhoria nos relacionamentos;

2 - Manutenção de um ambiente de trabalho, que proporcione motivação, valorização e reconhecimento das pessoas; e

3 - Aumento dos índices de produtividade e qualidade e a redução dos custos.

Utilização de Marketing de benefícios - salários indiretos - é considerado importante instrumento por Brum (1998). O pacote inclui: assistência médica e odontológica, um ambiente de trabalho saudável com programas de integração, lazer, recreação e prática de esportes. A divulgação desses benefícios considera-se um item importante para os programas.

\subsection{Programas de fidelização}

O bom marketing - o desenvolvimento de clientes fiéis e oferta de serviços de alta qualidade - não é limitado por fatores econômicos, e sim pela criatividade e determinação de vencer (Mckenna, 1999).

Elemento-chave do Marketing de Relacionamento, a fidelização bem-sucedida dos clientes considerados clientes todos os componentes da cadeia de valor da empresa, de fornecedor de matéria-prima até o consumidor final - aponta para a eficácia no programa da empresa. Marketing de Relacionamento está centrado na construção de relações duradouras e estáveis com os clientes da empresa e para isso o item mais importante é compreender as expectativas e as necessidades dos clientes, oferecendo produtos e serviços com a qualidade desejada.

Os comerciantes que ignoram o componente serviço em seus produtos concentram-se na diferenciação competitiva e nos instrumentos para penetrarem nos mercados. Os comerciantes que apreciam a importância do híbrido produto-serviço concentram-se no desenvolvimento de relações de fidelidade com o cliente (Mckenna, 1999, pg. 18).

Revista de Gestão Social e Ambiental - RGSA, São Paulo, v. 5, n. 3, p. X-XX, set./dez. 2011. 
Sheth e Parvatiyar (1995) apontam quatro motivos para os clientes manterem uma relação: (i) conseguir alta eficiência das decisões; (ii) reduzir a tarefa de coleção de informação sobre produtos, serviços; (iii) alcançar uma maior consistência cognitiva nas decisões; e (iiii) reduzir o risco associado com as decisões futuras. Essencial para a colaboração numa relação entre o cliente e a organização assenta-se no acréscimo de valor para as duas partes, expresso por aumento do custo ou redução da qualidade ao se mudar de fornecedor.

Para construir a fidelização, é essencial entender as necessidades, os desejos e os valores dos clientes, pois, a comunicação deve reforçar a percepção positiva sobre o produto ou serviço, com a mensagem certa, na hora certa. Os programas de fidelização realizam esforços de marketing específicos para determinados segmentos de mercado ou público-alvo. O diálogo sistemático com os clientes facilita à empresa obter dados relevantes para a formação do banco de dados dos clientes que, agregados aos dados de compra, permitem desenvolver estratégias de marketing customizadas e programas para indivíduos ou pequenos grupos de clientes, criando uma forte afinidade com a empresa (Bretzke, 2011). Um programa de fidelização é a persuasão customizada que parte da premissa de que nem todos os clientes são iguais.

Rapp e Collins (1991) enumeram algumas regras básicas para fidelização dos clientes, que são:

1. Desenvolver um ciclo de comunicação com o cliente: implica em elaboração e adoção de uma estratégia de comunicação que visa o intervalo entre o primeiro contato com o cliente até a obtenção da resposta desejada.

2. Fazer coisas com o cliente: apesar de ser considerado o melhor meio de interação entre a empresa e o cliente é o mais difícil de realizar.

3. Ouvir cuidadosamente: pode utilizar o Serviço Atendimento ao Cliente (SAC). Com esse serviço, a empresa oferece confiança e credibilidade ao produto. Os problemas e as dúvidas do cliente são resolvidos em tempo real. O registro das reclamações e sugestões pode ser utilizado na solução de problemas. Uma das melhores formas de atendimento e retenção do cliente - é um tratamento personalizado. Este serviço pode controlar a qualidade do atendimento e as possíveis falhas, auxiliando a sua eliminação. Ao permitir solução dos problemas em tempo hábil estreita o relacionamento com os clientes, conferindo maior credibilidade, confiança e valor à empresa.

4. Pesquisar respeitosamente: pesquisas sistemáticas das opiniões dos clientes permitem a elaboração e o aperfeiçoamento do Database Marketing. A pesquisa não pode ser feita de maneira a irritar o cliente. A experiência tem demonstrado a imensa utilidade do Customer Relationship Management (CRM) - as ferramentas informatizado que automatizam o relacionamento com os clientes.

5. Descobrir a força da propaganda de resposta direta: proporciona comunicação em busca de maiores informações e permite ao cliente anunciar a sua opinião a respeito da empresa.

6. Transformar compradores em adeptos: calcular o processo de adoção e de recompra para manter a comunicação fluindo nesse tempo.

Fundamentada em Rapp e Collins (1991), Bretzke (2011) apresenta os seguintes programas ou modelos de fidelização:

1. Modelo de Recompensas: através de bônus, prêmios ou incentivos, busca-se recompensar o cliente pelas compras sucessivas. Exemplo são os pontos de fidelidade para uso de certos cartões de crédito com direito a prêmios, programas de pontos nas linha aéreas, redução dos preços ou escolha dos quartos para hotéis etc.

2. Modelo Educacional: consiste em comunicação interativa que disponibiliza ao cliente conteúdos informativos a respeito dos serviços ou produtos. A ideia é "educar" o cliente a respeito das vantagens de uso do produto ou serviço. 
3. Modelo Contratual: formação de clube de clientes que possam usufruir de benefícios exclusivos via pagamento de taxa.

4. O Modelo de Afinidade: consiste em clube de clientes que agrega pessoas com interesse comum. O elemento agregador pode ser alguma publicação. A pertinência gera alto nível de resposta.

5. O Modelo do Serviço de Valor Agregado (ou adicional): alguma modalidade de serviço se agrega ao produto ou a um núcleo de serviço. Exemplo: algumas seguradoras acrescentam vários tipos de serviços não relacionados com o seguro feito, telefonia com SMS, fax, transporte até o hotel, hotel à disposição em viagens aéreas de longo alcance etc.

6. O Modelo de Aliança: consiste na junção de empresas a fim de prestar um serviço aos clientes comuns. Exemplo: as companhias aéreas que fazem a reserva de automóveis com locadoras de veículos ou reservas de hotel com determinadas redes de hotéis.

Os propósitos de cada um destes modelos são manter relacionamento no longo prazo, duradouro e estável, com determinados clientes. As empresas podem escolher um ou mais de um dos modelos acima para conseguir fidelizar os clientes. Rocha, et al. (2006) apresentam um exemplo de programa de fidelidade desenvolvido pela empresa Claro: o Claro Clube é um programa de fidelidade que se baseia em recompensa pela utilização do celular, de modo que o valor pago pelo cliente é transformado em pontos, que serão trocados por celulares e prêmios, além de descontos.

\section{MÉTODO DE PESQUISA}

A metodologia, segundo Santaella (2001), é a etapa da pesquisa em que se definem os métodos que fornecem os meios para chegar aos objetivos da pesquisa. Nesta fase é construído o modelo da pesquisa.

O objetivo da primeira etapa da pesquisa, caracterizada como exploratória, visou buscar a fundamentação teórica do trabalho. Os conceitos vinculados ao referencial teórico do tema, num estudo exploratório de múltiplos casos, segundo Boyd e Westfall (1986), é o primeiro passo do processo de pesquisa. $\mathrm{O}$ estudo exploratório apoia-se em diversas fontes de informação, sendo a primeira delas os dados secundários. Essas informações são as que, segundo Mattar (1996), já foram coletadas, tabuladas e ordenadas e orientarão a elaboração do questionário.

A pesquisa em dados secundários envolveu livros, revistas, teses e dissertações sobre o tema, pesquisa em anais de eventos científicos, banco de teses de várias Universidades. Esta foi a primeira aproximação que visa a criação de maior familiaridade com o tema. Nesta etapa foi realizada observação das seções de produtos orgânicos nas cadeias de supermercados Carrefour, Sondas e Pão de Açúcar, com finalidade de se identificarem as indústrias produtoras a participar da pesquisa.

A pesquisa em dados secundários, em um segundo momento, incluiu consultas a meios eletrônicos de busca na web, com o objetivo de investigar as indústrias produtoras de orgânicos e identificar suas estratégias de marketing de relacionamento para com o seu público interno e externo. Essa técnica, segundo Severino (1999), é uma fonte válida de informação. Junto examinaram-se certos documentos das empresas produtoras de orgânicos em estudo, tais como catálogos, relatórios e outros. Outra fonte de informação preliminar foram as pessoas com experiência - os dirigentes e pessoas ligadas à gestão dos programas de endomarketing e fidelização de clientes.

A segunda etapa consistiu na elaboração de um questionário fundamentado nas questões relevantes para o estudo, partindo da hipótese que o Marketing de Relacionamento em suas vertentes de programas de fidelização e de endomarketing seria estratégia relevante para se alcançar a sustentabilidade do setor do agronegócio que envolve os produtos orgânicos.

Revista de Gestão Social e Ambiental - RGSA, São Paulo, v. 5, n. 3, p. X-XX, set./dez. 2011. 
Os pontos principais investigados no questionário sobre programas de endomarketing diziam respeito à identificação (títulos ou ações dos programas oferecidos), objetivos, pessoas envolvidas. Para avaliação das ações e dos benefícios de tais programas voltados ao público interno, foram criadas categorias de análise, a partir da pesquisa bibliográfica.

A terceira etapa consistiu na pesquisa de campo. Foram aplicados dois questionários aos gestores, de uma amostra de 12 fabricantes de produtos orgânicos entre as 24 organizações investigadas e contatadas; assim a amostra da pesquisa foi por conveniência e envolveu 12 empresas. O primeiro questionário teve como objetivo analisar o perfil de cada programa de endomarketing por meio um questionário semi-estruturado. $\mathrm{O}$ segundo, com objetivo de levantar dados para análise de cada programa de fidelização de clientes e de endomarketing por meio de um questionário estruturado com escala tipo Likert, com cinco níveis de resposta. A elaboração dos itens pesquisados acompanhou a fundamentação teórica.

O questionário voltado aos programas de fidelização indagou os gestores sobre o perfil dos segmentos priorizados e sobre as ações que faziam parte de tais programas, sendo que essas últimas também foram definidas tendo como base o referencial teórico. Foram investigados os instrumentos utilizados na gestão do relacionamento com clientes: pesquisa mercadológica, uso de CRM (no questionário, identificado como "sistema computadorizado"), comunicação, atendimento ao pósvenda e o SAC (Serviço de Atendimento ao Cliente ).

\section{RESULTADOS DA PESQUISA}

Todas as empresas pesquisadas possuem programas de fidelização. $75 \%$ contam com Serviço de Atendimento ao Consumidor (SAC); 33\% buscam divulgar receitas em seus próprios sites; $25 \%$ recorrem ainda para merchandising dos produtos; $17 \%$ das empresas pesquisadas disponibilizam profissionais da saúde para prestação de serviços ao consumidor e esclarecimento de dúvidas.

No tocante ao tempo de vigência dos programas de fidelização, todos os entrevistados confirmaram a introdução desses programas com prazo mínimo de um ano. Os objetivos do programas de fidelização listados pelas empresas foram: buscar a satisfação do cliente; reparar reclamações; enviar amostras para degustação nos pontos de venda; entregar os produtos no prazo acordado a fim de melhorar a qualidade do serviço prestado; divulgar novos produtos e tentar introduzir novos hábitos de consumo; realçar a distinção dos produtos orgânicos em relação aos convencionais; mostrar a inter-relação que existe entre todos os elementos que compõem o meio ambiente e a produção de orgânicos; promover visitas periódicas de inspeção por agricultores, processadores, acadêmicos, técnicos e representantes dos consumidores; fazer análise residual para verificar o nível de pureza do produto e aprovação da unidade de produção, dentro dos padrões de qualidade orgânica e informar os clientes; melhorar o atendimento e a comunicação com o cliente; destacar os benefícios do consumo de orgânicos em relação à qualidade de vida; agregar valor e aumentar o nível de confiança da linha de produtos; Coletar embalagens, enviar para reciclagem e trocar por brindes para os consumidores dos produtos - realçando a preocupação das empresas com o meio ambiente; visitar clientes e abrir novos mercados; participar de feiras.

Em relação aos segmentos priorizados pelos programas de fidelização nas empresas produtoras de orgânicos, 11 das 12 organizações pesquisadas indicaram os clientes regulares que compram da empresa regularmente.

Entre as empresas pesquisadas, oito indicaram que priorizam os compradores satisfeitos com a experiência inicial e passam a fazer negócios com a empresa. Metade das empresas investigadas busca priorizar os clientes experimentadores, representados por pessoas que tomam conhecimento da empresa e de suas ofertas por meio de primeiras compras experimentais. Das 12 empresas,

Revista de Gestão Social e Ambiental - RGSA, São Paulo, v. 5, n. 3, p. X-XX, set./dez. 2011. 
quatro investem nos clientes eventuais, aqueles que já foram conquistados, mas que ainda mantêm fontes alternativas para seus negócios de orgânicos.

De acordo com as respostas nos questionários, 11 das empresas pesquisadas afirmam que o programa de fidelização se mostra eficaz para criação de relacionamento duradouro e estável com os clientes. Sete das doze empresas pesquisadas direcionam as ações de seus programas de fidelização para aumentar o volume de vendas com os clientes já conquistados. Metade das empresas investigadas busca nas ações dos programas de fidelização atender consumidores mais frequentes, com maior gasto médio, sendo essas ações contínuas e de longo prazo.

Em quatro das empresas investigadas, os programas de fidelização atendem qualquer comprador, independentemente do seu perfil. Para duas empresas, as ações dos programas planejadas em um prazo determinado oferecem recompensa para o cliente no curto prazo. Apenas uma empresa tem como ação os programas de fidelização que oferecem recompensas para o cliente no longo prazo.

Das 12 empresas investigadas, nove utilizam os meios de comunicação como instrumentos da gestão do relacionamento com clientes. Sete organizações indicaram que utilizam o SAC como principal instrumento para o relacionamento com os clientes. Cinco empresas utilizam a pesquisa mercadológica para, ao conhecer melhor as necessidades dos clientes, promover melhoras no relacionamento. Três firmas investem no atendimento pós-venda e apenas duas empresas utilizam sistema computadorizado como instrumento para a gestão do relacionamento com os clientes.

Enquanto o programa de fidelização é realidade em todas as empresas da amostra, dez organizações contam com programa de endomarketing. Com base nos dados coletados, as organizações que investem em programas de endomarketing já o desenvolvem há mais de um ano. O tempo máximo de vigência desse programa implementado pelas empresas pesquisadas é de 11 anos. As informações indicaram o envolvimento dos colaboradores dessas empresas e os resultados indicaram que os tipos dos programas de endomarketing visavam melhorar a qualidade de vida dos colaboradores por meio de várias ações.

As empresas indicaram também que os objetivos dos programas de endomarketing envolvem: sensibilização das atitudes e da prática de ações que possam promover o bem-estar dos colaboradores (por meio de atividades de educação nutricional, sobre lazer, atividades físicas, sobre como tratar o estresse e outros problemas); conscientização em relação aos cuidados com o meio ambiente; prevenção de possíveis problemas com os produtos; apresentação de novos produtos para os colaboradores, para favorecer o processo de vendas; distribuição interna de amostras no lançamento de produtos; transparência ao informar os colaboradores sobre assuntos organizacionais; reconhecer e valorizar a diversidade étnica e cultural; integrar os colaboradores à cultura da empresa; Trabalhar ininterruptamente na capacitação e no desenvolvimento dos colaboradores; incentivar a iniciativa e manter a motivação valorização e reconhecimento dos colaboradores; desenvolver ações em benefício dos clientes; evitar o distanciamento entre as áreas da empresa; melhorar índices de produtividade; reduzir custos; desenvolver a flexibilidade no ambiente de trabalho; apresentar os resultados alcançados, mensalmente, para toda a equipe; e fazer pesquisa sobre o e clima organizacional e efetuar correções se necessárias.

Cinco das empresas da amostra responderam que concordam totalmente com as afirmações que o programa de endomarketing estimula a participação dos colaboradores da organização, melhoram as atitudes e comportamentos em relação às suas ocupações, criam e promovem ideias inovadoras nas organizações voltadas ao bom atendimento ao cliente.

Quatro empresas concordam totalmente que os programas de fidelização utilizam pesquisas para identificar as necessidades e desejos dos colaboradores, incluem benefícios para satisfazer as expectativas dos funcionários, atraem, desenvolvem e retém talentos, asseguram que todos os colaboradores tenham as informações necessárias para agir em benefício dos clientes. Buscam a manutenção de um ambiente de trabalho que proporcione motivação, valorização e reconhecimento das pessoas, utilizando canais de comunicação interna a fim de conseguir melhoria nos 
relacionamentos, independentemente do nível hierárquico, e utilizam o treinamento sob a ótica de educação e desenvolvimento dos colaboradores. Três das firmas concordam com as afirmações que os programas de endomarketing estimulam os colaboradores, a adoção da missão, visão, objetivos, estratégias e táticas do negócio.

Quanto à melhora dos índices de produtividade, apenas sete empresas concordam parcialmente que os programas de endomarketing contribuem para este objetivo. Cinco firmas concordaram parcialmente com a afirmação de que os programas de endomarketing melhoraram as atitudes e comportamentos dos colaboradores em relação ao emprego. Apenas quatro organizações concordam, e só parcialmente, que os programas de endomarketing, nos quais são elaboradas pesquisas para identificar as necessidades e desejos dos colaboradores, asseguram as informações necessárias para agir em benefício dos clientes. Entretanto, essas empresas afirmaram ter criado ambientes e situações que motivam os seus funcionários, contribuindo, desse modo, para a melhoria dos índices de qualidade e para a superação das resistências internas ás mudanças. Três empresas concordaram parcialmente com a afirmação que os programas de endomarketing estimulam a adoção da missão, visão, objetivos, estratégias e táticas do negócio.

Somente cinco das organizações investigadas concordam que os programas de endomarketing, que incluem os planos de carreira como instrumentos de motivação, favorecem o recrutamento e seleção. Para quatro das firmas pesquisadas, os programas de endomarketing contribuem para a redução dos custos. Para os dirigentes de três das empresas da amostra, os programas de endomarketing não atingem completamente os objetivos de criação de um ambiente de crescimento individual para grande parte dos colaboradores nos níveis operacional, intermediário ou gerencial.

\section{ANÁLISE E DISCUSSÃO DOS RESULTADOS}

Ao identificar os programas desenvolvidos no âmbito do marketing de relacionamento na tentativa de alcançar a sustentabilidade na sua vertente econômica dos produtos orgânicos, verificou-se que todas as empresas investigadas implementaram programas de fidelização dos clientes. Os instrumentos mais utilizados pelas indústrias de produtos orgânicos para alcançar o público alvo encontrado na pesquisa foram Serviço de Atendimento ao Cliente (SAC), orientações de profissionais da área da saúde quanto aos benefícios do consumo de alimentos orgânicos, assim como receitas culinárias que utilizam os produtos.

Analisando os programas de fidelização, verificou-se que o tempo de vigência varia de $1 \mathrm{a}$ 16 anos. Comparando-se os resultados da introdução dos programas de endomarketing com os de fidelização, verificou-se o foco é ainda o cliente externo e somente com o tempo se introduz o programa de endomarketing.

Os objetivos declarados dos programas de fidelização nas indústrias de orgânicos pesquisadas são: satisfação dos clientes; reparação de erros; envio de amostras; divulgação de novos produtos; entregas no prazo; informações sobre a utilização dos produtos; melhoria do atendimento, comunicação com os clientes.

O segmento de clientes priorizado foi basicamente de clientes regulares, ou seja, aqueles que compram da empresa há algum tempo e cuja principal ação dos programas de fidelização é criar um relacionamento permanente entre cliente e empresa.

A avaliação das empresas pesquisadas quanto alcance dos resultados dos programas de fidelização indica o impacto positivo no longo prazo - exatamente o resultado almejado. Os programas de fidelização preveem comunicação constante com os clientes para compreensão de suas necessidades e para auxílio na construção de segmentações consistentes com o objetivo de transformar os produtos e serviços em maior valor para os clientes. As empresas relataram que

Revista de Gestão Social e Ambiental - RGSA, São Paulo, v. 5, n. 3, p. X-XX, set./dez. 2011. 
buscam inovações constantes na maneira de fazer o negócio e há métodos previstos para mensuração e divulgação dos resultados obtidos com as ações dos programas de fidelização.

Os instrumentos mais utilizados pelas empresas investigadas na gestão do relacionamento com os clientes são os meios de comunicação, entre os quais podem ser citados: Internet, telefone, revistas, panfletos, jornais e revistas. Quanto ao uso das ferramentas informatizadas que auxiliam e automatizam o relacionamento com os clientes, apenas duas empresas usavam essas ferramentas.

O Marketing de Relacionamento está centrado na construção de relações duradouras e estáveis com os clientes e, como já enfatizado na fundamentação teórica. Para alcançar este objetivo, o item mais importante citado na teoria consiste na compreensão das expectativas e as necessidades dos clientes para oferecer produtos e serviços com a qualidade desejada. Neste sentido, as evidências coletadas na amostra de empresas pesquisadas confirmam as proposições do referencial teórico.

Quanto aos modelos teóricos de fidelização apresentados na parte teórica do artigo as empresas de produtos orgânicos da amostra em investigação utilizam o Modelo Educacional, que usa a comunicação interativa e disponibiliza ao cliente conteúdos informativos a respeito dos produtos.

Ao identificar a existência de programas de marketing de relacionamento desenvolvidos pelas indústrias desse segmento para o público interno (programas de endomarketing), ficou evidenciado que a maioria das empresas possui programas de endomarketing (10 empresas das 12 empresas pesquisadas), sendo os tipos de programas oferecidos ligados à capacitação, cultura organizacional, comportamento, mudança e clima organizacional.

Sobre o tempo de vigência dos programas de endomarketing, há variação desde os com três meses até 11 anos de implementação. Os objetivos dos programas de endomarketing estavam direcionados, de acordo com os depoimentos, para a promoção do bem-estar; para a busca do comprometimento, capacitação e informação dos colaboradores. Os maiores benefícios oferecidos pelos programas de endomarketing, apontados pelas empresas, foram: estimula a participação de todos os colaboradores da organização; melhora as atitudes e comportamentos dos colaboradores; cria e promove ideias nas organizações voltadas ao bom atendimento ao cliente; contribuir para a melhoria dos índices de produtividade; favorecer o recrutamento e seleção; incluir os planos de carreira como instrumentos de motivação. Em relação ao aspecto de abrangência dos programas de endomarketing, constatou-se que todos os colaboradores dessas organizações foram envolvidos.

Enquanto os programas de fidelização dos clientes foram implantados em todas as empresas e acompanham os pontos teóricos, exceto a introdução do Customer Relationship Management (CRM) - utilizado por apenas duas das empresas da amostra -, os programas de endomarketing foram implementados em 10 das empresas. Além disso, o tempo de vigência deste programa foi substancialmente menor em relação ao tempo de introdução dos programas de fidelização.

\section{CONSIDERAÇÕES FINAIS}

A pesquisa permite concluir que o marketing de relacionamento é uma resposta para a inovação dos produtos orgânicos e uma diretriz mercadológica para as indústrias de orgânicos. Finaliza-se, assim, o estudo com as evidências de que as indústrias de produtos orgânicos da amostra praticam quase integralmente o marketing de relacionamento, utilizando os programas de fidelização e de endomarketing. Teoricamente, estes são os principais instrumentos para a prática mercadológica quando se trata de bens de crença, característica dos produtos orgânicos, devido às dificuldades de o consumidor avaliar suas qualidades desejáveis, mesmo depois de seu consumo.

Os instrumentos mercadológicos não são as únicas ações com capacidade de contribuir para o alcance da sustentabilidade econômica do setor de produtos orgânicos. Entre as outras medidas há a certificação e a rastreabilidade que não são o objeto deste estudo. Entretanto, estas duas exigências têm recebido a atenção da academia, enquanto não há estudos sobre a adequação das ações mercadológicas.

Revista de Gestão Social e Ambiental - RGSA, São Paulo, v. 5, n. 3, p. X-XX, set./dez. 2011. 
Como sugestão para estudos futuros, consideramos a necessidade da ampliação do número de organizações, bem como identificar lacunas na oferta. Nessa linha, ainda, podem ser desenvolvidas pesquisas de oportunidade mercadológica e de estratégias de diversificação de produtos que possam contribuir para a sustentabilidade econômica desse segmento. Completando a sugestão para estudos futuros, pesquisas sobre o comportamento de consumidores de produtos orgânicos.

\section{REFERÊNCIAS}

BEKIN, S. Conversando sobre endomarketing: um ciclo de entrevistas com Saul Faingaus Bekin. São Paulo. Makron, 1995.

BERRY, L. L. (1983). Relationship marketing. In L. L. Berry, G. L. Shostack; G. Upah. (Eds.), Emerging Perspectives on Services Marketing (pp. 25-28). Chicago, IL: American Marketing Association, 1983.

BID/FUMIN, Relatório de Avaliação Final do Programa de Rede Comunitária de Acesso ao Mercado para Produtores Orgânicos - OrganicsNet. BID/FUMIN. Operação ATN/ME 10485-BR Projeto BR-M1051, BID/FUMIN, Rio de Janeiro, 05 de agosto de 2010. Disponível em: < http://idbdocs.iadb.org/wsdocs/getdocument.aspx?docnum=35594509>. Acesso em: 12/09/2011.

BOYD, H. W.; WESTFALL, R. Pesquisa mercadológica. São Paulo: FGV, 1986.

BRASIL. Ministério da Agricultura, Pecuária e Abastecimento.Cadeia produtiva de produtos orgânicos. Brasília: MAPA, 2007. (Série Agronegócios).

BRETZKE, M. (2011). Sistema de fidelização: como encantar o seu cliente. Disponível em: <http://www.bretzke-marketing.com.br/textos/artigos09.htm>. Acesso em: 18/06/2011.

BRETZKE, M; RIBEIRO, Á.; DOURADO, Y. Marketing de Relacionamento: Oportunidade para Desenvolvimento e Crescimento Contínuo no Setor Financeiro. Balas, 1998. Disponível em: <http://www.bretzke-marketing.com.br/textos/artigos08.htm>. Acesso em: 06/10/2010.

BRUM, A. Endomarketing como estratégia de gestão: encante seu cliente interno. Porto Alegre: L\&PM, 1998.

BRUM, A. Um Olhar sobre o marketing interno. Porto Alegre: L\&PM, 2000.

BRUM, A. M. Endomarketing de A a Z: como alinhar o pensamento das pessoas à estratégia da empresa. São Paulo: Integrare, 2010.

CAMELO, M. B.;VIDAL, M. B. O endomarketing a partir da perspectiva de aprendizado e crescimento do balanced scorecard. Anais... do IV Simpósio de Gestão e Estratégia em Negócios, Seropédica, RJ, 2006.

DAROLT, M. Agricultura orgânica: inventando o futuro. Londrina: IAPAR, 2001.

DAVIS, S. Futuro perfeito. São Paulo: Nobel, 1990.

Revista de Gestão Social e Ambiental - RGSA, São Paulo, v. 5, n. 3, p. X-XX, set./dez. 2011. 
DOUGLAS, E. J. Managerial economics: analysis and strategy. 4th ed., New Jersey: Prentice-Hall International Editions, 655p, 1992.

EMPRESA BRASILEIRA DE PESQUISA AGROPECUÁRIA - Embrapa. Agrobiologia. Sistemas de Produção, 2 - $2^{\text {a }}$ Edição, ISSN 1806-2830 Versão Eletrônica, Dez. 2006. Disponível em:<http://sistemasdeproducao.cnptia.embrapa.br>. Acesso em: 18/07/2011.

GOODLAND, et al.(eds.) Medio ambiente y desarrollo sostenible: más allá del Informe Brundtland. Madrid: Editorial Trotta, 1997.

GRÖNROOS, C. Quo Vadis, Marketing? Toward a Relationship Marketing Paradigm. Journal of Marketing Management, No. 10, 1994.

INKOTTE, Alexandre Luiz. Endomarketing: elementos para a construção de um marco teórico. 2000. Dissertação (Mestrado em Engenharia de Produção) - Centro Tecnológico, Universidade Federal de Santa Catarina, Florianópolis. 131f. Disponível em: http://teses.eps.ufsc.br/defesa/pdf/3009.pdf Acesso em: 13/02/2011.

KOTLER, P. Administração de marketing: análise, planejamento, implementação e controle. São Paulo: Atlas, 1993.

KOTLER, P; ARMSTRONG, G. Princípios de marketing. Rio de Janeiro: Prentice-Hall, 2000.

KOTLER, P.; ARMSTRONG, G. Princípios de marketing. São Paulo: Pearson, 2007.

MATTAR, F. N. Pesquisa de marketing. São Paulo: Atlas, 1996.

McKENNA, R. Marketing de Relacionamento. Rio de Janeiro: Campus: São Paulo, 1999.

OLBRZYMEK, J. R.; OLBRZYMEK, M. R.; BRETZKE, R. O. Marketing de relacionamento: grandes projetos não envolvem somente tecnologia. Agathos Revista Científica da Asssevim, ano 1, edição 001, 2005.

RAPP, S.; COLLINS, T. 5a Geraçao Do Marketing Maximarketing II. São Paulo: Makron Books, 1991.

ROCHA, T. et al. O uso de programas de fidelidade como instrumento para retenção de clientes no mercado de telefonia móvel. Um estudo de caso. Anais... do IX SemeAd - Seminários em Administração FEA/USP, São Paulo, SP, 2006.

ROSENBERG, L. J.; CZIEPIEL, J. A. A Marketing Approach to Customer Retention, Journal of Consumer Marketing, Vol. 1, Spring, pp.45-51, 1984.

SANTAELlA, L. Comunicação e Pesquisa: Projetos para Mestrado e Doutorado. São Paulo: Hacker Edite, 2001.

SEROA da MOTTA, R. Desafios ambientais da economia brasileira. São Paulo: IPEA 1997.

SEVERINO, A. J. Metodologia do trabalho científico (19a ed.). São Paulo: Cortez, 1999.

SHETH, J. N.; PARVATIYAR, A. The evolution of relationship marketing. International Business Review, [S.1.], 4(4), 471-481,1995. 
SOUZA, M.C.M. Produtos orgânicos. In: ZYLBERSZTAJN, D.;NEVES,M.F. (org). Economia e Gestão dos Negócios Agro-alimentares. São Paulo: Pioneira, 2000.

WORLD COMMISSION ON ENVIRONMENT AND DEVELOPMENT (WCED). Our common Future. Oxford: Oxford University Press, 1987.

Data do recebimento do artigo: 07/12/2011

Data do aceite de publicação: 